ARTICLE

DOI: $10.1057 /$ s41599-018-0140-6

\title{
Hydro-social metabolism: scaling of birth rate with regional water use
}

\author{
Saket Pande ${ }^{1} \&$ Akshay Pandit ${ }^{1}$
}

\begin{abstract}
Population growth is often intuitively linked with proportionally higher use of fresh water resources. However, this implies that water use per capita does not change with population growth. We not only find that birth rates of regions are negatively related with its water use per capita (i.e., higher birth rate is associated with lower water use), but also that birth rates scale with the latter with a negative power. We use population and water withdrawal data from 1950 to 2005 at irregular 5-year intervals; with virtual water content, virtual water trade and agricultural production data from 1960 to 2000 for the seven continents to investigate the scaling relationship and interpret it through the lens of metabolism theory. Our analysis reveals that the scaling exponent lies between $-1 / 3$ and $-1 / 2$. Deviations from the power relationship are observed for Europe and Africa, which are attributed to lower than expected and higher than expected birth rates, respectively. Europe's deviation from the average scaling relationship may be due to the higher rate of return on human capital in industrialized countries. But why Africa deviates, while other developing and developed regions follow the power relationship more closely, remains a puzzle.
\end{abstract}

\footnotetext{
${ }^{1}$ Department of Water Management, Delft University of Technology, Delft, Netherlands. Correspondence and requests for materials should be addressed to S.P. (email: s.pande@tudelft.nl)
} 


\section{Introduction}

W ater is the medium through which nutrients and oxygen are transported at a rate that is needed to sustain human life. The metabolic demand of a growing population determines the rate at which water is withdrawn and used for agricultural production. If the rate of water use is limited (e.g., due to technology or water scarcity), then a high birth rate is not sustainable unless it is complemented by a higher mortality rate.

Metabolism, which is a process of transforming energy and materials for work or biomass generation, is one key process that has been hypothesized to control birth rates of multiple species, as well as flux exchange between species or constituents of an ecosystem (Hou et al., 2008; Brown et al., 2004). The metabolic rate, $B$, has been found to scale with exponent $3 / 4$ with mass, $M$ :

$$
B \propto M^{3 / 4} .
$$

And other biological rates such as reproduction rate, $r$, have been found to be proportional to metabolic rate per unit mass:

$$
r \propto B / M=M^{-1 / 4} \text {. }
$$

The above two expressions suggest that $r \propto B^{-1 / 3}$ (i.e., reproduction rate scales with the metabolic rate with an exponent of $-1 / 3)$. The power scaling has been widely reported across more than 20 orders of magnitude of mass, from single cell organisms to plants and mammals (Moses and Brown, 2003). Given the biochemical reactions behind metabolism, its rate is expected to be limited by the rate at which materials are supplied to the reactions, or that it controls the rate at which materials are used, such as by the rate of water use by humans.

Mechanistic models of metabolism theory interpret the emergence of scaling relationship as a result of space-filling properties of networks, such as of blood vessels, that transport materials to reaction sites (Banavar et al., 2002; Savage et al., 2008). The argument behind the emergence of the scaling relationship has often been that such networks have evolved to be efficient (e.g., in terms of minimizing energy loss) (Bettencourt, 2013). In general, such models predict $r \propto B^{-1 / D}$ scaling relationship when a transport network efficiently fills a $D$-dimensional space (Banavar et al., 2002; Savage et al., 2008).

Power scaling relationships between birth rates and proxies of metabolic rates, such as calorie intake per capita (Burger et al., 2011; Burger et al., 2017) and Gross Domestic Product based income per capita (Zhang and Yu, 2010; Bauch, 2008), have been reported elsewhere. Figure 1 reports a similar, statistically significant $-1 / 3$ scaling relationship between birth rate and GDP per capita of the seven continents. Indeed, the negative correlation can be interpreted in terms of changes that are facilitated by increasing income per capita, such as women empowerment, opportunity cost to raise children, and transition from communal to societal demographics with more nuclear families (Mace, 2008; Bettencourt et al., 2007; Lutz, 2006). However, unlike economic theory, metabolism theory offers an interpretation, not only for the negative correlation but also for the scaling relationship.

Since population growth, food security, and economic production are tightly linked with water use (Pande et al., 2014; Srinivasan et al., 2017), this paper takes a metabolism theory view on the relationship between birth rate and regional water use for the first time. Given that metabolism is the transformation of matter and energy, and that water is the medium of material fluxes, we investigate whether the average metabolic rate of humans control (or is controlled by) water use per capita, which in turn influences birth rate. This paper finds statistically significant evidence of the scaling of average birth rates with water use per capita of the seven continents (See Materials and Methods for its interpretation). This is based on the analysis of birth rates and different water use per capita variables at regional scale, using temporal data sets on water withdrawals, virtual water content and trade of agricultural commodities, and population growth. Table 1 and Materials and Methods (subsection "Data sets used") explain the variables that follow, including five water use related variables: WDR, USE, VWP, VWC, and $\mathrm{VWC}_{e}$.

\section{Materials and methods}

Interpretation. Assume for simplicity that there is one livestock type and one crop type, and that humans feed on both livestock and crops while livestock feed only on crops (3 trophic levels, see Bonhommeau et al., 2013). Any growth in human biomass should be balanced by growth in livestock biomass and growth in crop biomass that are used in human diet, multiplied by corresponding assimilation efficiencies. Similarly, growth in livestock biomass should be balanced by growth in crop biomass used in livestock feed. If $N$ is human population, $N_{c}^{\mathrm{H}}$ is the number of crops used in human diet, $M_{\mathrm{c}}$ is the average mass of the crop, $N_{\mathrm{L}}^{\mathrm{H}}$ is the number of livestock used in human diet, $M_{\mathrm{L}}$ is the average mass of livestock and $N_{c}^{\mathrm{L}}$ is the number of crops used in livestock diet then

$$
\begin{aligned}
N r M & =\rho_{\mathrm{c}}^{\mathrm{H}} N_{\mathrm{c}}^{\mathrm{H}} r_{\mathrm{c}} M_{\mathrm{c}}+\rho_{\mathrm{L}}^{\mathrm{H}} N_{\mathrm{L}}^{\mathrm{H}} r_{\mathrm{L}} M_{\mathrm{L}} \\
& =\left(\rho_{\mathrm{c}}^{\mathrm{H}} N_{\mathrm{c}}^{\mathrm{H}}+\rho_{\mathrm{L}}^{\mathrm{H}} \rho_{\mathrm{c}}^{\mathrm{L}} N_{\mathrm{c}}^{\mathrm{L}}\right) r_{\mathrm{c}} M_{\mathrm{c}}
\end{aligned}
$$

where $r_{c}$ and $r_{L}$ are reproduction rates of crops and livestock. Variables $\rho_{\mathrm{c}}^{\mathrm{H}}, \rho_{\mathrm{c}}^{\mathrm{L}}$, and $\rho_{\mathrm{L}}^{\mathrm{H}}$ are efficiencies (between 0 and 1) of assimilating crops by humans, crops by livestock and livestock by humans, respectively. Equation (1) balances the growth in human biomass by the growth in livestock and crop biomass that are used in human diet. The second equation incorporates the balance of growth in livestock biomass by the growth in crop biomass used in livestock feed. If $N_{c}^{\mathrm{T}}=N_{c}^{\mathrm{H}}+N_{c}^{\mathrm{L}}$ is the total amount of crops grown both to feed humans and livestock, then the growth in human biomass should be matched by the total growth in crop biomass that is directly or indirectly assimilated by humans:

$$
N r M=\rho_{\mathrm{e}}^{\mathrm{H}} N_{\mathrm{c}}^{\mathrm{T}} r_{\mathrm{c}} M_{\mathrm{c}} .
$$

Here, $0<\rho_{\mathrm{e}}^{\mathrm{H}}<1$ represents effective efficiency of assimilating crops (directly or indirectly via livestock) by humans. From Eq. (1) it is given by $\rho_{\mathrm{e}}^{\mathrm{H}}=\left(\rho_{\mathrm{c}}^{\mathrm{H}} N_{\mathrm{c}}^{\mathrm{H}}+\rho_{\mathrm{L}}^{\mathrm{H}} \rho_{\mathrm{c}}^{\mathrm{L}} N_{\mathrm{c}}^{\mathrm{L}}\right) / N_{\mathrm{c}}^{\mathrm{T}}$, which essentially is a weighted (by respective assimilation efficiencies) sum of crops consumed directly by humans and livestock. The left side of Eq. (2) is the total growth in human biomass, and the right side, which follows from Eq. (1), is the fraction of the total growth in crop biomass that has been effectively assimilated by humans.

Following Savage et al. (2004), $r_{\mathrm{c}} M_{\mathrm{c}} \propto M_{\mathrm{c}}^{3 / 4} \propto B_{\mathrm{c}}$, where $B_{\mathrm{c}}$ is the average metabolic rate of the crop. Given that the metabolic rate is the transformation rate of matter and energy, and water is the medium of material fluxes (i.e., nutrients from the soil up to the leaves), we assume that $B_{\mathrm{c}}$ is proportional to average use of water, $w_{c}$, by the crop. From Eq. (2), this means that $N r M \propto \rho_{\mathrm{e}}^{\mathrm{H}} N_{\mathrm{c}}^{\mathrm{T}} B_{\mathrm{c}} \propto \rho_{\mathrm{e}}^{\mathrm{H}} N_{\mathrm{c}}^{\mathrm{T}} w_{\mathrm{c}}$. Since total water use of crops used to feed humans is given by $w_{c}^{\mathrm{T}}=N_{\mathrm{c}}^{\mathrm{T}} w_{\mathrm{c}}$, we then obtain:

$$
r M \propto \rho_{\mathrm{e}}^{\mathrm{H}} N_{\mathrm{c}}^{\mathrm{T}} w_{\mathrm{c}} / N=\rho_{\mathrm{e}}^{\mathrm{H}} w_{\mathrm{c}}^{\mathrm{T}} / N .
$$

Then, the evidence that $r \propto\left(w_{c}^{T} / N\right)^{-1 / 3}$ can be interpreted as resulting from the following relationships: $r M \propto M^{3 / 4} \propto B$ with variation in effective assimilation efficiency considered negligible (see subsection "trophic levels and effective assimilation efficiency" below). This is because then $r \propto B^{-1 / 3}$ and would imply 


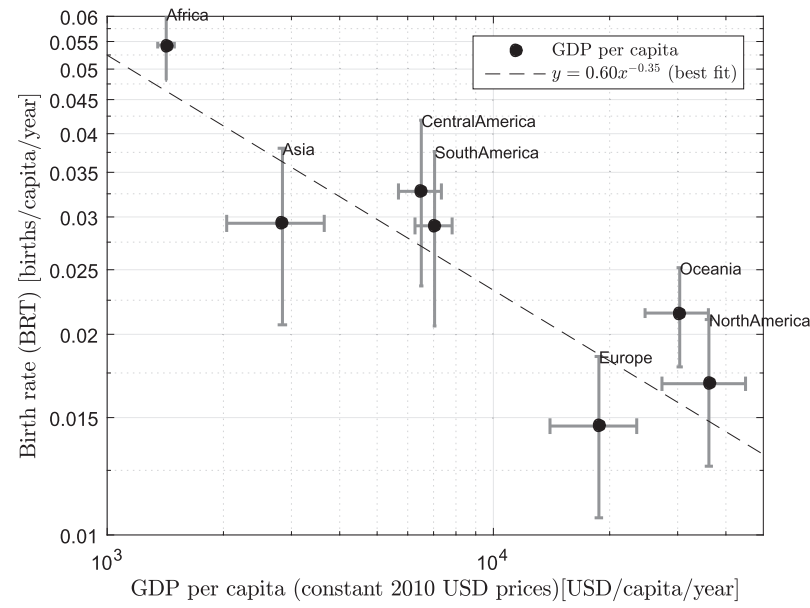

Fig. 1 Scaling of birth rates (BRT) with Gross Domestic Product (GDP) per capita of regions. Also shown is the corresponding best fit line ("random effect estimation"). GDP per capita scales with BRT with power -0.35 (similar to fixed effect estimation: not shown). See Table 1 for definitions and Material and Methods section for panel data analysis

that average metabolic rate of humans is proportional to its water use per capita (by substituting $B=w_{c}^{\mathrm{T}} / N$ ).

Note that in the derivation above, temperature and other climate effects on water use per unit crop biomass produced have been ignored (in addition to the assumption that water that is used by humans and livestock directly is negligible compared to $w_{c}^{T}$ ) because $w_{c}$ is assumed to be independent of where the crops are grown. However, the above interpretation will still hold if $w_{c}^{\mathrm{T}}$ is obtained from actual calculations that incorporate temperature effects (e.g., based on total water withdrawals or water footprints and virtual water trade of regions, as detailed in the subsection "Data sets used").

Data sets used. Seven regions are considered based on UN classification (United Nations, (2018)): Asia, Africa, Central America (including the Caribbean), Europe (including Russian Federation post-1990 and USSR pre-1990), North America, South America, and Oceania.

$B R T$. Birth and population data per year are obtained from United Nations (2015). Average number of births per year over 5year periods from 1951-2000 are divided by population in the middle of the corresponding periods to obtain birth rate, BRT.

On water use variables, we distinguish between two types. One type of water use variable is based on water withdrawals (either by humans through irrigation or by plants from the root zone; also interchangeably called footprint) that does not incorporate parts of water use that are virtually imported. This type of variables include WDR and VWP (see Table 1, indicated in gray). The other type of water use variables adjust water withdrawals by incorporating net virtual water imports. This second type of variables include USE, VWC, and $\mathrm{VWC}_{\mathrm{e}}$.

Net virtual water import variables, depending on the data sources used, are $\mathrm{NWI}_{\mathrm{SH}}$ and $\mathrm{NWI}_{\mathrm{HK}}$. Net virtual water import $\mathrm{NWI}_{\mathrm{SH}}$ is estimated based on the following steps (Hoekstra and Hung, 2002): (1) FAO methodology is used to estimate crop water requirement of crops grown that consider country-specific climate conditions relevant for potential evaporation (e.g., temperature), (2) FAOSTAT based yield and crop production data that estimate conservative water footprint values, and (3) COMTRADE based trade in agricultural commodities data that then enables the estimation of net virtual water imports for the

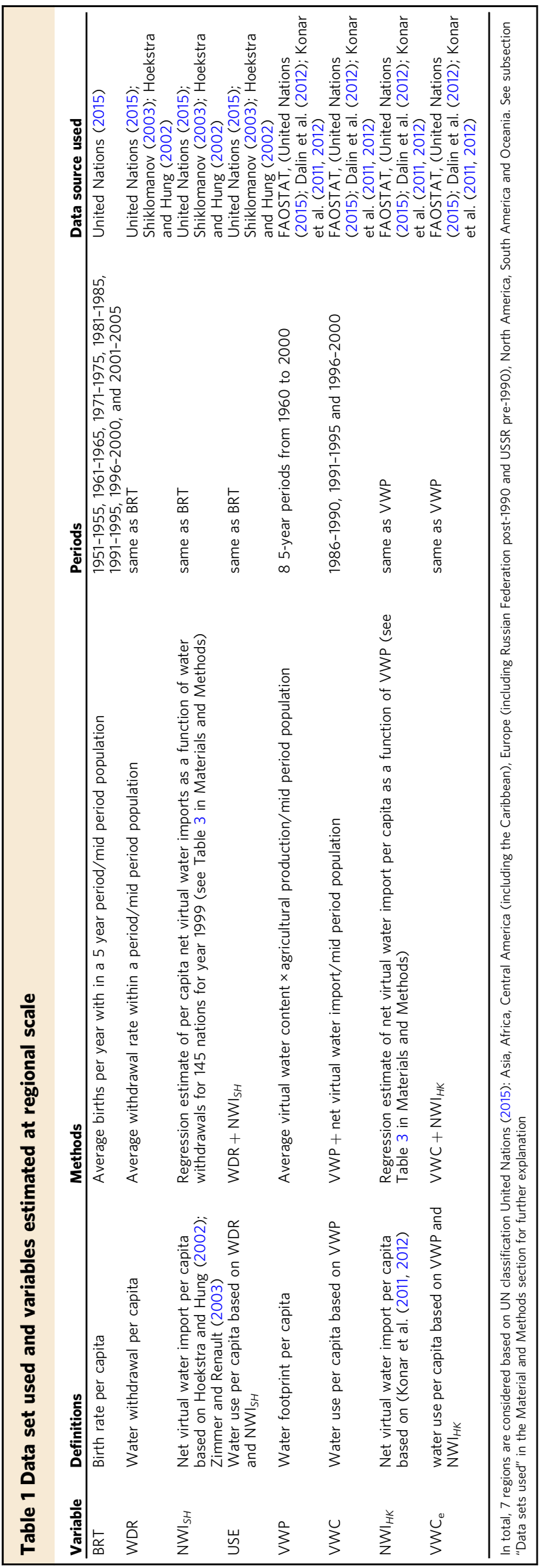


regions. Similarly, the estimation of $\mathrm{NWI}_{\mathrm{HK}}$ is based on the estimation of water footprint (VWP) that is based on the estimation of gridded crop specific transpirations and yields as a function of climate (e.g., rainfall and temperature) and soil water holding characteristics, while distinguishing between rainfed and irrigated agriculture based on land cover maps and using FAOSTAT and COMTRADE commodity trade data to estimate net virtual water imports (Dalin et al., 2012; Konar et al., 2012; Konar et al., 2011; Hanasaki et al., 2010).

The water use variables can also be distinguished based on data sources used. WDR, USE, and $\mathrm{NWI}_{\mathrm{SH}}$ are based on Shiklomanov (2003) and Hoekstra and Hung (2002) that are further described below.

WDR. The water withdrawals per capita (WDR) are obtained by dividing regional water withdrawals (Shiklomanov, 2003) for years 1950,1960,1970,1980,1990,1995, and 2000 by the population of the regions in the middle of the periods 1951-55, 1961-65, 1971-75, 1981-85, 1991-95, 1996-2000, and 2001-2005. The water withdrawals are total, including agriculture that accounts for almost $80 \%$. Other purposes are for domestic water use and industrial water use. Regional water withdrawals are based on national statistics of specific water use or by country analogs (i.e., countries with similar physiography, including climate, and economic development) and population statistics.

USE. Water use of a region is defined as the sum of 'real' water physically withdrawn for agricultural production and the 'virtual' water that is imported or exported through trade in agricultural (crop and livestock) products. WDR of regions is adjusted for net virtual water import rates per capita $\left(\mathbf{N W I}_{\mathbf{S H}}\right.$, derived from Hoekstra and Hung (2002) and Table 3 of Zimmer and Renault (2003)) to obtain one calculation for regional water use per capita (USE). Net virtual import rates are the rates at which regions virtually import water through the imports of (mostly agricultural) commodities minus the rates at which regions virtually export water through commodity exports. Since the calculations in Hoekstra and Hung (2002) are provided for 1995, we hypothesize (and validate using independent data sets based on FAOSTAT, Konar et al. (2012), Konar et al. (2011), and Hanasaki et al. (2010)-see variables VWP, VWC, and $\mathrm{VWC}_{\mathrm{e}}$ below and subsection "Net virtual water import as a function of water footprint") that net virtual water import of a region is proportional to WDR. We then use this proportionality to extrapolate net virtual water import $\left(\mathrm{NWI}_{\mathrm{SH}}\right)$ to other periods of the study.

The extrapolation is based on a regression analysis across 145 countries between water withdrawals per capita and net virtual water import per capita for the year 1995 (Hoekstra and Hung, 2002) (See Fig. 2). Regional water use per capita (USE) for all seven 5-year periods is then calculated as the sum of WDR and $\mathrm{NWI}_{\mathrm{SH}}$ estimated for these periods as a function of WDR. WDR is 'blue' water because it is extracted by man-made infrastructures. However, $\mathrm{NWI}_{\mathrm{SH}}$ (net virtual water import) is composed of both 'blue' and 'green' water use, but it is obtained as a function of 'blue' water withdrawal. Therefore, USE is both 'blue' and 'green' water.

Another set of water use variables is based on FAOSTAT, Konar et al. (2012), Konar et al. (2011) and Hanasaki et al. (2010). Related variables are VWP, VWC, $\mathrm{VWC}_{\mathrm{e}}$, and $\mathrm{NWI}_{\mathrm{HK}}$.

$V W P$. To investigate the validity of $\mathrm{NWI}_{\mathrm{SH}^{-}}$WDR relationship and the limitation of using only WDR ('blue' water since it is withdrawn and does not account for rain fed water use), we use virtual water content data (Dalin et al., 2012) of five major crops (barley, corn, rice, soybeans, wheat) and three major livestock products (beef, pork, poultry) from 1961 to 2000. These are then

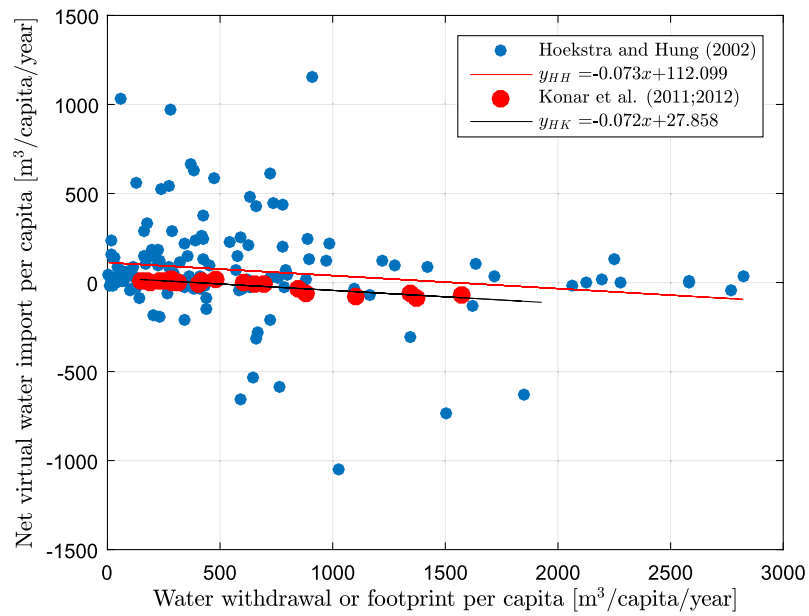

Fig. 2 Regression between net virtual water imports per capita and water withdrawals or water footprint per capita. Also shown are respective best fit linear models (details in Table 2). The data labeled 'Hoekstra and Hung (2002)' are based on net virtual water imports from Hoekstra and Hung (2002) for 145 nations for year 1999 and'Konar et al. (2011; 2012)' is based on net virtual water imports based on Konar et al. (2011; 2012) for the regions and span periods 1986-1990, 1991-1995, and 1996-2000.

Similarity in the slopes of the best fit lines, i.e., the proportional relationship between total water withdrawals (footprint) per capita and net virtual water import (trade) per capita, is evident. See Table 1 for definitions and Table 2 for regression results

multiplied with country specific production values (obtained from FAOSTAT) to obtain total water footprint of nations. The regional water footprint is then obtained as the sum of constituting national water footprints, where regions are based on the UN classification system. The time series are averaged over every 5-year interval from 1961 to 2000 (e.g., 1961-1965, 1966-1970, and so on), and divided by regional populations in the middle of such intervals to obtain period specific regional water footprint per capita (VWP). National virtual water imports and exports for the same agricultural commodities (Konar et al., 2011; 2012) are used from 1986 to 2000 to similarly calculate regional net virtual water import rate for three periods: 1986-1990, 1991-1995, and 1996-2000 (net total = total import-total export, where total is the sum over all the agricultural commodities considered). These are then divided by regional population in the middle of corresponding periods to obtain regional net virtual water import per capita.

Regional net virtual water import per capita and water footprints per capita (VWP) are used to independently validate the $\mathrm{NWI}_{\mathrm{SH}^{-}}-\mathrm{WDR}$ relationship (that higher net exporters per capita also have higher water footprint per capita) for the three periods. This is further discussed below (subsection "Net virtual water import as a function of water footprint") and shown in Fig. 2.

Two additional estimates of regional water use per capita (to complement USE) are calculated. These are based on virtual water content and trade data, data sets that are independent of the data sets used for calculating USE.

VWC. The first one is VWC, which is calculated for periods 1986-1990, 1991-1995, and 1996-2000 by taking the sum of VWP and regional net virtual water import per capita based on Konar et al. (2011, 2012).

$V W C_{e}$. The second one is $\mathrm{VWC}_{\mathrm{e}}$. The relationship between regional net virtual water import per capita Konar et al. 
(2011, 2012) and water footprint per capita, shown in Fig. 2, is used to 'back calculate' water use $\left(\mathrm{VWC}_{\mathrm{e}}\right)$ of regions from 1961 to 2000 at 5-year intervals. This is based on regressing regional net virtual water import per capita based on Konar et al. $(2011,2012)$ with VWP to obtain $\mathbf{N W I}_{\mathbf{H K}}$ (See Fig. 2 and Table 2, and subsection "Net virtual water import as a function of water footprint"). These two estimates of water use, VWC and $\mathrm{VWC}_{e}$, are then further used to validate the scaling relationship between birth rate and water use per capita.

Changes in irrigated crop lands are part of WDR, which are based on specific withdrawal rates and irrigated areas. Differences in specific withdrawals rates (e.g., withdrawal rate per hectare to irrigate) between regions incorporate the differences in technologies. $\mathrm{NWI}_{\mathrm{SH}}$ uses yield data from FAOSTAT that incorporates different crops grown in different countries. Finally, VWP and $\mathrm{NWI}_{\mathrm{HK}}$ are based on the H08 model (Hanasaki et al., 2010) that uses gridded crop cover data set. Since for irrigation the H08 model incorporates water withdrawal data from national statistics of AQUASTAT, changes in technology between regions for water withdrawal for irrigation are implicitly incorporated.

Net virtual water import as a function of water footprint. The transition from water withdrawal and water footprint to water used for regional consumption requires adjustments based on virtual water trade. In order to be able to extrapolate the relationship between net virtual water import per capita and water footprint per capita to the past, we investigate whether the observed relationship across the regions also applies to unobserved time periods. Figure 2 plots net virtual water import of 145 nations that lie within 3 standard deviations from the mean with corresponding withdrawal rate per capita for the year 1995 based on Hoekstra and Hung (2002). The best fit line is also shown, which suggests that net virtual water import per capita scales linearly with water withdrawal per capita by a factor of -0.073 at 95\% confidence level (see Table 2). The linear relationship is significantly better than a constant (i.e., no relationship) model in explaining the relationship between net virtual water import per capita and water withdrawal per capita of nations.

This suggests that nations that withdraw larger amounts of water per capita are also more likely to virtually export more water per capita. This may be because nations that withdraw more water per capita for production activities, such as agricultural production, do so partly for exports to other nations.

This is validated by demonstrating a similar relationship between regional net virtual water import per capita and VWP for three periods: 1986-1990, 1991-1995, and 1996-2000. Note that these calculations are at the regional scale. The best fit line has the

Table 2 Extrapolating net virtual water imports to the past

\begin{tabular}{|c|c|c|}
\hline & Estimate & Standard error \\
\hline \multicolumn{3}{|c|}{$\begin{array}{l}\text { a) } N W I_{S H} \text { estimation, i.e., } y_{S H}, N=145, R_{\mathrm{p}}=-0.17, p \text {-value v. constant } \\
\text { model }=0.047\end{array}$} \\
\hline \multicolumn{3}{|c|}{$\begin{array}{l}\text { b) } \mathrm{NWI}_{\mathrm{HK}} \text { estimation, i.e., } y_{H K}, N=21, R_{\mathrm{p}}=-0.90, p \text {-value v. constant } \\
\text { model }<0.01\end{array}$} \\
\hline $\begin{array}{l}\text { Intercept } \\
\text { Slope }\end{array}$ & $\begin{array}{l}27.858^{\mathrm{a}} \\
-0.072^{\mathrm{a}}\end{array}$ & $\begin{array}{l}5.340 \\
0.007\end{array}$ \\
\hline
\end{tabular}

a) $\mathrm{NWI}_{\mathrm{SH}}$ estimation: regression statistics between national net virtual water imports per capita a) $\mathrm{NWI}_{\mathrm{SH}}$ estimation: regression statistics betwe

and water withdrawals per capita (WDR) and
b) $\mathrm{NWI}_{\mathrm{HK}}$ estimation: regression statistics between regional virtual water imports per capita and water footprint per capita (VWP)

${ }^{a}$ indicates significance level of $<0.01$ and

$\mathrm{b}_{\text {indicates significance level of } 0.05}$ same slope, of -0.072 at $<0.01$ significance level (see Table 2). This supports our assumption that net virtual water import per capita is proportional to water used per capita for productive activities at regional scale in unobserved periods.

Trophic levels and effective assimilation efficiency. Trophic level of humans at regional scale varies between 2 and 2.5 (Bonhommeau et al., 2013). Trophic level of 2.5 means that human diet is composed of livestock and crops in equal amounts (in mass). This means that the crop biomass grown for direct human consumption should be equal to the animal biomass grown for human consumption. Or, $N_{\mathrm{c}}^{\mathrm{H}} r_{\mathrm{c}} M_{\mathrm{c}}=N_{\mathrm{L}}^{\mathrm{H}} r_{\mathrm{L}} M_{\mathrm{L}}$, where the left side is the crop biomass being produced for human consumption while the right side is the livestock biomass being produced for human consumption. But $N_{\mathrm{L}}^{\mathrm{H}} r_{\mathrm{L}} M_{\mathrm{L}}=\rho_{\mathrm{c}}^{\mathrm{L}} N_{\mathrm{c}}^{\mathrm{L}} \mathrm{r}_{\mathrm{c}} M_{\mathrm{c}}$ because the biomass that livestock grow (left side) should be equal to the crop biomass that livestock consume (right side). These two equalities lead to a restriction that the number of crops consumed by livestock should be equal to the number of crops consumed by humans divided by the efficiency of assimilating crops by livestock (i.e., $N_{\mathrm{c}}^{\mathrm{L}}=N_{\mathrm{c}}^{\mathrm{H}} / \rho_{\mathrm{c}}^{\mathrm{L}}$ ). Plugging this into effective assimilation efficiency, we obtain a special restriction for effective assimilation efficiency when the trophic level of humans is 2.5: $\rho_{\mathrm{e}}^{\mathrm{H}}=\rho_{\mathrm{c}}^{\mathrm{L}}\left(\rho_{\mathrm{c}}^{\mathrm{H}}+\rho_{\mathrm{L}}^{\mathrm{H}}\right) /\left(1+\rho_{\mathrm{c}}^{\mathrm{L}}\right)$. When trophic level is 2 , the restriction on effective assimilation efficiency is $\rho_{\mathrm{e}}^{\mathrm{H}}=\rho_{\mathrm{c}}^{\mathrm{H}}$ (i.e., the effective assimilation efficiency is the efficiency of assimilating crops by humans).

Assuming conservative assimilation efficiencies (i.e., $\rho_{\mathrm{c}}^{\mathrm{H}}=\rho_{\mathrm{c}}^{\mathrm{L}}=$ 0.20 and $\left.\rho_{\mathrm{L}}^{\mathrm{H}}=0.80\right)$, corresponding effective efficiencies $\rho_{\mathrm{e}}^{\mathrm{H}}$ can be shown to vary between 0.20 (for trophic level 2) and 0.19 (for trophic level 2.5). Assuming optimistic assimilation efficiencies, i.e., $\rho_{\mathrm{c}}^{\mathrm{H}}=\rho_{\mathrm{c}}^{\mathrm{L}}=0.5$ and $\rho_{\mathrm{L}}^{\mathrm{H}}=0.8, \rho_{\mathrm{e}}^{\mathrm{H}}$ varies between 0.50 (for trophic level 2) and 0.43 (for trophic level 2.5). In both the cases the variation in effective assimilation efficiency $(0.01-0.07)$ is less than 0.10 , which is one order lower than the magnitudes of effective assimilation efficiency (0.19-0.50). Meanwhile, the variation in water use per capita is between 200 and $1400 \mathrm{~m}^{3} /$ year/capita (which is a variation of $1200 \mathrm{~m}^{3}$ /year/capita; see e.g., Fig. 1), which is of the same order as water use per capita. We therefore can assume that regional variation in effective assimilation efficiency is negligible compared to the scale of variation in regional water use per capita.

Panel data analysis. A panel of data here is defined as period specific. That is, a panel of data is defined as birth rate and water use data of regions for a given period. Depending on the water use variable used, panels of data cover periods from 1951-1955 to 2001-2005 (see Table 1).

Let $z_{\mathrm{ti}}$ be the log of birth rate of region $i$ for period $t$, and $X_{\mathrm{ti}}$ be the log of water use of corresponding region and time period. A panel data model is given by

$$
z_{\mathrm{ti}}=\alpha_{0}+X_{\mathrm{ti}} \beta+\alpha_{t}+\varepsilon_{\mathrm{ti}}
$$

where $\alpha_{t}$ represents region invariant time period specific 'fixed effect,' $\alpha_{0}$ is region and time period invariant effect, $\varepsilon_{\mathrm{ti}}$ is the residual with $\varepsilon_{\mathrm{ti}} \sim$ i.i.d $\left(0, \theta_{\varepsilon}^{2}\right)$ (i.e., independently and identically distributed variable with mean 0 and variance $\theta_{\varepsilon}^{2}$ ), and $\beta$ is the slope (exponent of the power relationship). If $X_{\mathrm{ti}}$ is independent of period specific fixed effects $\alpha_{t}$, then one may as well estimate random effect model:

$$
z_{\mathrm{ti}}=\alpha+X_{\mathrm{ti}} \beta+\varepsilon_{\mathrm{ti}} .
$$

Table 3 reports "random effect" estimates of $\beta$ using this equation for $z=\log (y)$ and $X=\log (x)$. 


\begin{tabular}{|c|c|c|c|c|c|}
\hline \multirow[t]{2}{*}{$x$} & \multirow[t]{2}{*}{$\boldsymbol{N}$} & \multicolumn{2}{|c|}{ Random effect estimate } & \multicolumn{2}{|c|}{$\begin{array}{l}\text { Dynamic panel fixed effect } \\
\text { estimate }\end{array}$} \\
\hline & & $\begin{array}{l}\beta \text { (standard } \\
\text { error) }\end{array}$ & $R_{p}$ & $\begin{array}{l}\beta \text { (standard } \\
\text { error) }\end{array}$ & $R_{p}$ \\
\hline $\begin{array}{l}\text { WDR } \\
\text { USE } \\
\text { VWP } \\
\text { VWC } \\
\text { VWC }_{e}\end{array}$ & $\begin{array}{l}49 \\
49 \\
56 \\
21 \\
56\end{array}$ & $\begin{array}{l}-0.504(0.107) \\
-0.582(0.125) \\
-0.371(0.076) \\
-0.468(0.108) \\
-0.390(0.081)\end{array}$ & $\begin{array}{l}-0.564 \\
-0.560 \\
-0.551 \\
-0.704 \\
-0.547\end{array}$ & $\begin{array}{l}-0.526(0.101) \\
-0.408(0.109) \\
-0.438(0.062) \\
-0.427(0.071) \\
-0.455(0.066)\end{array}$ & $\begin{array}{l}-0.564 \\
-0.560 \\
-0.550 \\
-0.703 \\
-0.547\end{array}$ \\
\hline \multicolumn{6}{|c|}{$\begin{array}{l}\text { A panel consists of regional data for a time period. Hence, depending on the water use data used } \\
\text { from Table } 1 \text {, we have } 7 \text { (for WDR and USE) to } 3 \text { panels (VWC). The estimated regression } \\
\text { relationship is } y=e^{\alpha} x^{\beta} \text { with } y \text { being BRT and } x \text { being different water use variables defined in } \\
\text { Table } 1 \text {. Only estimations of } \beta \text { are reported. Random effect estimate assumes that there are no } \\
\text { panel specific effects (to be otherwise catured by } \alpha \text { ) while dynamic panel fixed effect model } \\
\text { assumes not only that there are time period specific fixed effects but also that panel data are } \\
\text { auto-correlated. Standard errors of parameter estimates are shown in the parenthesis alongside. } \\
\text { Also shown are corresponding correlation coefficients, } R_{p} \text {, between observed and predicted } y \text {. } \\
\text { The power estimates, } \beta \text {, of the scaling relationship between water use and birth rates are } \\
\text { statistically significant (at significance level of }<0.01 \text { ) and lies between }-1 / 3 \text { and }-1 / 2 \text {. See } \\
\text { Materials and Methods section for details on panel data analysis implemented here }\end{array}$} \\
\hline
\end{tabular}

However, $\varepsilon_{t i}$ may be auto-correlated, thereby not obeying the assumption that $\varepsilon_{t i}$ is independently distributed over time, due to co-variates that are not currently being considered alongside water use. Examples of such co-variates can include national policy related variables and opportunity cost of raising children that may systematically change over time. Since the presence of auto-correlated errors can lead to biased estimate of the effect if the autocorrelation is ignored from the model, we use dynamic panel data model with fixed effect to incorporate auto-correlated residuals,

$$
\begin{gathered}
z_{\mathrm{ti}}=\alpha_{0}+X_{\mathrm{ti}} \beta+\alpha_{\mathrm{t}}+\varepsilon_{\mathrm{ti}}, \\
\varepsilon_{\mathrm{ti}}=\varphi \varepsilon_{(t-1) \mathrm{i}}+v_{\mathrm{ti}}
\end{gathered}
$$

Here, all the variable definitions remain the same as in Eq. (4), except that $\varepsilon_{\mathrm{ti}}$ is modeled as an auto-correlated variable (AR1 process) with an auto-correlation of $\theta_{\mathrm{v}}^{2} \varphi /\left(1-\varphi^{2}\right)$, and $v_{\mathrm{ti}}$ is an independently and identically distributed variable with mean 0 and variance $\theta_{\mathrm{v}}^{2}$. Table 3 also reports the "dynamic panel fixed effect" estimates of $\beta$ using Eq. (5a) and Equation b, for $z=\log (y)$ and $X=\log (x)$.

The panel models are estimated using a panel data toolbox for MATLAB (Álvarez et al., 2017).

\section{Results}

Figure 3 shows the plot of birth rate (BRT) with water withdrawal per capita (WDR) of regions from 1950 to 2000. The slope of the best linear fit, in log-log space, has a slope of -0.5 . Also, for comparison, shown is the variation of regional water footprint based on Dalin et al. (2012) (VWP) with BRT for period 1961 to 2000 and the corresponding best linear fit (in log-log space) that has a slope of -0.37 . Both the best fit lines have significant slopes $(<0.01$ significance level, see Table 3$)$. While both WDR and VWP are classified as water footprint quantities, the difference between the two is that WDR considers 'blue' water while VWP incorporates both 'green' and 'blue' water (see "Data sets used" subsection of Materials and Methods). Also, the two estimations are not from the same data set and do not use the same methodology. In spite of that, the two estimates of water used for regional production of agricultural products, which are either consumed or exported, demonstrate a significant power

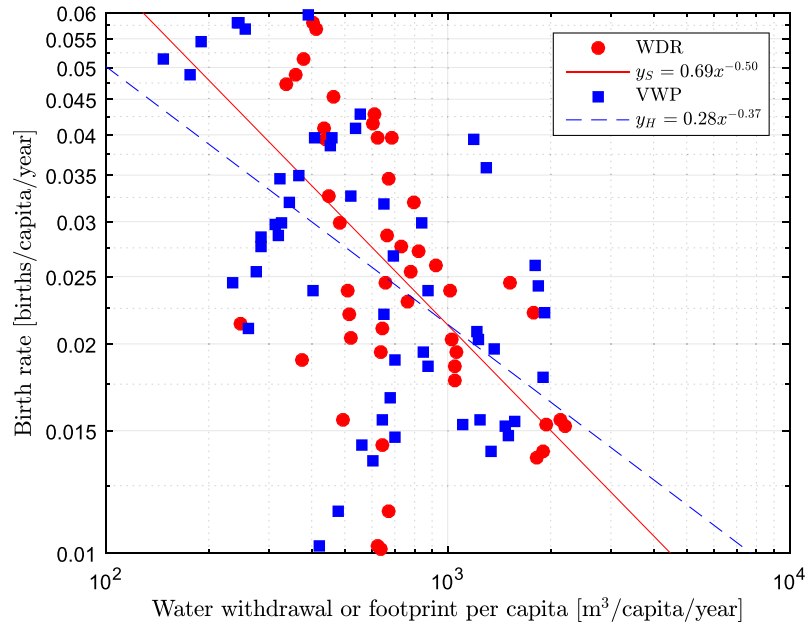

Fig. 3 Scaling of birth rates (BRT) with water withdrawals (WDR) and water footprint (VWP) of regions. Also shown are corresponding best fit lines corresponding to "random effect estimation" (dependent variable $y_{s}$ corresponds to WDR and $y_{h}$ corresponds to VWP). WDR scales with BRT with power -0.50 while VWP scales with BRT with power -0.37 , both significant at $<0.01$ level. See Table 1 for definitions, Table 3 for slope estimations and Material and Methods section for panel data random effect estimation

relationship scaling with regional birth rate (with the power lying between -0.50 and -0.37 ).

Table 3 provides regression results between BRT $(y)$ as the dependent variable and various estimated water use related variables (WDR, USE, VWP, VWC, and $\mathrm{VWC}_{\mathrm{e}}$ ) as the independent variable $(x)$, taken one at a time. The regression model is $y=e^{\alpha} x^{\beta}$, following a power relationship hypothesis, where $e^{\alpha}$ corresponds to $\alpha$ in log space that can either be considered as random or fixed time period specific effect (see subsection "Panel data analysis" in Materials and Methods).

All regressed exponents, i.e., $\beta$, are significant at $<0.01$ level and lie between -0.58 and -0.37 , assuming random effect (i.e., assuming there is no time period specific fixed effect). The relationship between BRT and VWC is the strongest (correlation coefficient, $R_{\mathrm{p}}$, is $\left.\sim-0.70\right)$. While the estimate of $\beta$ moves from -0.50 in case of WDR to -0.58 in case of USE, it moves from -0.37 when using VWP as the explanatory variable to -0.46 when using VWC.

Dynamic panel data analysis (see subsection "Panel data analysis" in Materials and Methods), which essentially estimates $\beta$ while considering regional data of a time period as belonging to one panel with its own fixed effect and incorporating autocorrelations in the data, reveals stronger results. All estimated exponents are significant at $<0.01$ level and in general clutter around -0.44 . The estimate of $\beta$ moves from -0.52 in case of WDR to -0.41 in case of USE, and moves from -0.44 when VWP is the explanatory variable to -0.43 when using VWC.

Figure 4 compares the dynamic panel slope with period specific regressed slopes between BRT and VWC for the 3 periods for which corresponding data was available and finds no systematic variation between the periods. Further, the differences in slopes between period specific regressions and panel data regression indicate that there is more information in the data when data sets from different periods are taken together than when they are analyzed per period.

In both random effect and dynamic fixed effect panel data analysis, the estimates of $\beta$ based on $\mathrm{VWC}_{\mathrm{e}}$ are -0.39 and -0.45 , respectively. Finally, estimates of $\beta$ based on VWP, VWC, and $\mathrm{VWC}_{\mathrm{e}}$ (i.e., regional water use per capita calculations based on 


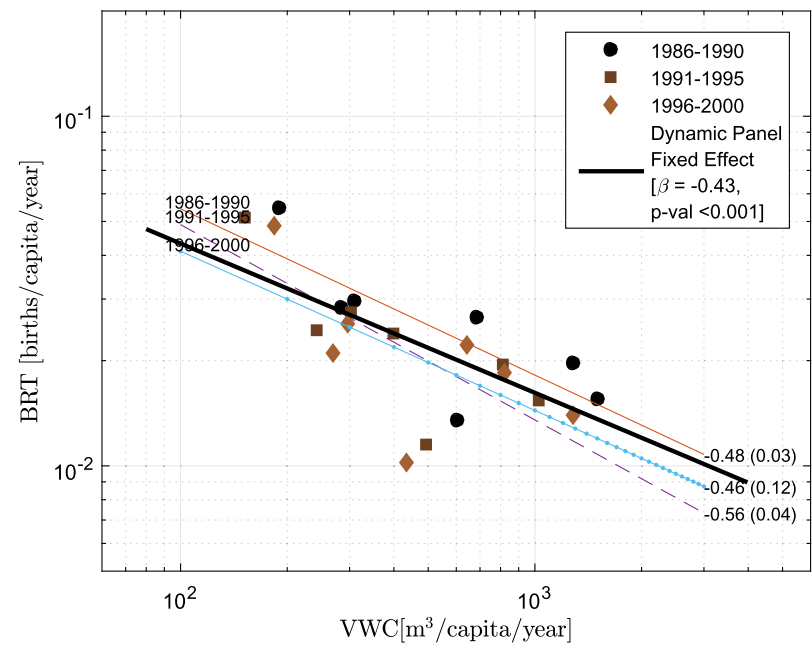

Fig. 4 Period specific scaling of birth rate (BRT) with VWC for the three periods for which VWC data was available. Values shown alongside the best fit lines are corresponding periods and values of corresponding slopes with $p$-values shown in the parentheses. Also shown is the dynamic panel fixed effect estimation. There is no systematic variation in the estimated slopes. The dynamic panel estimate further demonstrates the value of simultaneously considering different periods in estimating the slope

regional virtual water content and trade in agricultural commodities) validate the observation made based on WDR and USE (based on regional water withdrawal rates) that birth rates scale with water use per capita with an exponent that is in between $-1 / 2$ and $-1 / 3$.

Figure 5 presents similar information as Fig. 3 except that temporal variation per region is shown in whiskers for two water use per capita variables, USE (water use estimated based on water withdrawals) and VWC (water use based on virtual water content and trade), along the $x$-axis and birth rate, BRT, along the $y$-axis. Also shown are lines with slopes estimated based on corresponding dynamic panel data analysis (shown in Table 3 under "dynamic panel fixed effect"). Both yield similar scaling pattern between birth rates and water use per capita of regions.

\section{Discussion}

If each period of regional data is considered as a panel then the estimation of exponent $(\beta)$ reported in Fig. 3, i.e., the slopes of the lines, are random effect estimations (see "Panel data analysis" in Materials and Methods). On the other hand, the estimates of $\beta$ reported in the slope of lines in Fig. 5 are fixed effects estimates based on a dynamic panel data model that incorporates autocorrelation in data between successive periods. Auto-correlated error often appears as a result of auto-correlated variables, which when not considered in an analysis lead to biased estimation of the effect. Once the autocorrelation is accounted for, the power estimates move closer to -0.44 . This also suggests that the effective dimension of the network that distributes metabolites for human growth lies in between 2 and 3 .

Lower birth rates, such as in North America, Europe, and Oceania, are associated with higher per capita water consumption. Developing regions demonstrate the contrary. While regions appear to deviate from the power relationship, the statistical analysis results shown in Table 3 suggest that the power relationship is statistically significant in explaining the variance in data. Thus regions with higher birth rates have lower water use per capita.

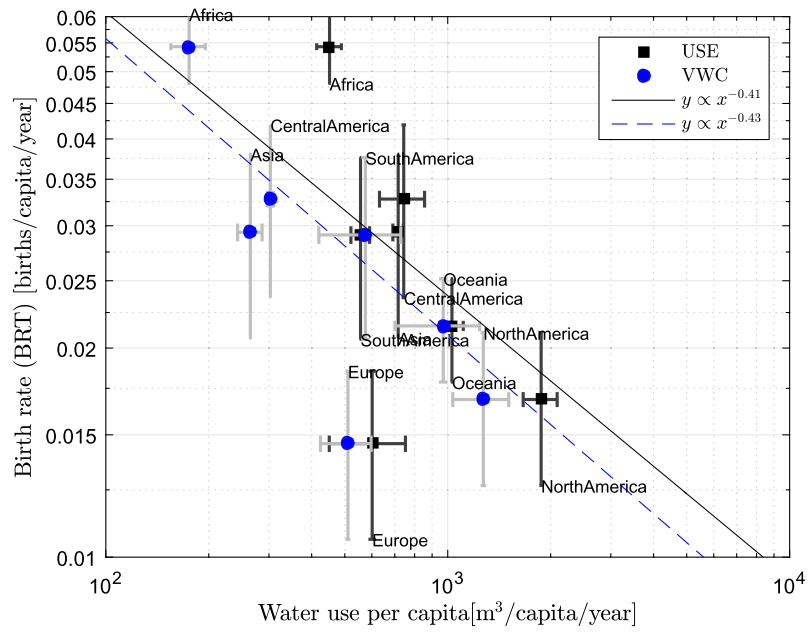

Fig. 5 Scaling of birth rates with water use of regions based on USE and VWC. The whiskers show \pm 1 standard deviation around the mean value. The solid black line has the slope that corresponds to "dynamic panel fixed effect" estimate of power $\beta$ for BRT vs. USE data while the dashed blue line corresponds to the dynamic panel fixed effect estimate of $\beta$ for BRT vs. VWC data. VWC shows scaling relationship similar to that between BRT and USE. Africa, Asia and Central America appear to have largest differences between USE and VWC, possibly due to large difference between blue and total water footprint. See Table 1 for definitions, Table 3 for $\beta$ estimation and Material and Methods section for dynamic panel fixed effect estimation

Similar scaling relationship is also found between birth rate and GDP per capita (Fig. 1; Zhang and Yu, 2010; Bauch, 2008). However, socio-economic changes that come along with economic development such as women empowerment, opportunity cost to raise children and transition from communal to societal demographics with more nuclear families can only explain a decreasing trend with development. It also falls short of explaining why water use per capita is increasing with increasing GDP per capita because technological innovation that comes along with rising GDP per capita should increase water use efficiency and thereby reduce water use per capita. Such efficiency paradox has been reported extensively, especially in context of irrigation, where it has been argued that a profit maximizing producer will increase the level of an input if more efficient technologies reduce the marginal cost of producing/extracting the input per unit price of output (Alcott, 2005; Sears et al., 2018 and references within). For example, if drip irrigation is made available that reduces the marginal cost of applying irrigation by reducing non-productive soil evaporation, then the farmer will increase his production by applying more irrigation. However this assumes that other inputs such as land, seeds, etc. are not binding the producer and that it costs to extract water. It remains unclear whether this is the case at regional scale.

Metabolism theory provides an interpretation of the observed scaling relationship with a negative exponent, with GDP per capita serving as proxy for average metabolic rate of regions. The interpretation is based on the observation that water use drives agricultural production (see "interpretation" in Materials and Methods). Water use proportionately drives not only the GDP of the agricultural sector but also the availability of food and energy for other economic activities-thereby providing population means to buy food, consume and reproduce. Such causal interpretation is elaborated in Fig. 6, which decomposes the relationship between BRT and VWP into two relationships. The first is between birth rate and net agricultural production per capita and the second one is between net agricultural production per 


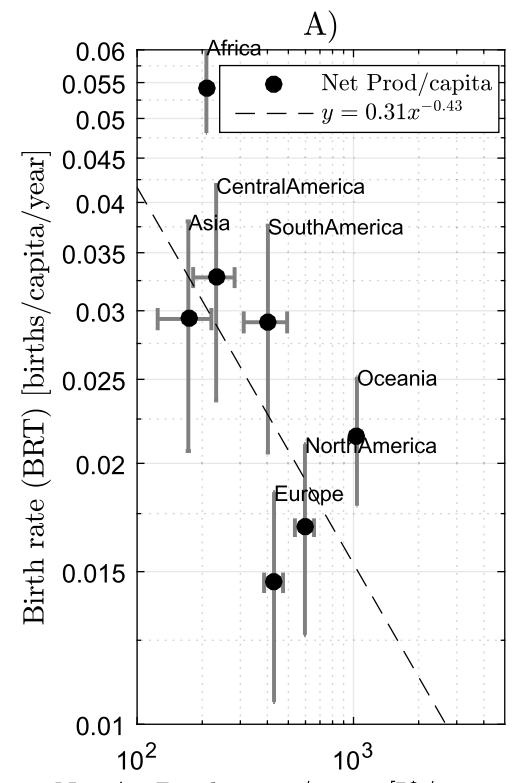

Net Ag Production/capita[I\$/capita/year]

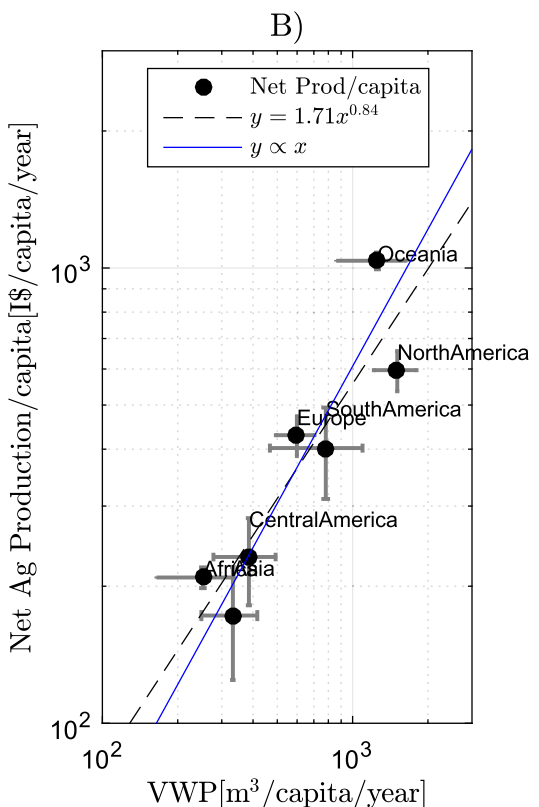

$\operatorname{VWP}\left[\mathrm{m}^{3} /\right.$ capita/year $]$

Fig. 6 Decomposition of the scaling relationship between BRT and VWP into (a) BRT and net agricultural production per capita and (b) net agricultural production per capita and VWP. Net agricultural production per capita is valued in 2004-2006 international dollars per capita per year. Also shown in figure panels $\mathbf{a}, \mathbf{b}$ are best fit lines using dynamic panel data analysis with slopes of -0.43 and 0.84 , respectively that are statistically significant at $<0.01$. Figure panel $\mathbf{b}$ also shows least biased line with a slope of 1 that is expected. The multiplication of the two slopes, $-0.43 \times 0.84$, yields a value of -0.36 that is close to the reported slope of BRT vs. VWP power relationship in Table 3

capita and VWP. Net agricultural production per capita excludes agricultural outputs that are used as inputs to other agricultural production processes. Further, net agricultural production per capita is expressed in international dollars (I\$) in order to express production of regions in a unit of currency that has the same purchasing power parity that US dollar had in the United States in period 2004-2006.

Figure 6a shows a pattern similar to Fig. 3 with the slope of the best fit line of -0.43 at significance level $<0.01$. Figure $6 \mathrm{~b}$ shows that net agricultural production per capita scales sub-linearly with VWP with a power of 0.83 at a significance level of $<0.01$. An approximate scaling exponent of -0.36 between birth rate and VWP can thus be imputed by multiplying -0.43 with 0.83 , which is close to the value of -0.44 reported in Table 3 . Figure $6 \mathrm{~b}$ also shows least biased line with slope of 1 , which is expected if water is the limiting factor in agricultural production (see also "interpretation" in Materials and Methods section). The two sloped lines in Fig. 6b indicate that regions such as Africa and Asia use less than expected water per capita for their level of production (the best fit line is below the $y \propto x$ line) while developed regions such as North America and Oceania use more than expected water per capita for their level of production.

This observed deviation from the expected can be interpreted in I = PAT way of thinking (Chertow, 2000), which argues that consumption of resources increases with affluence per capita. This can also be interpreted as resulting from dis-economies of scale effect, that more developed economies with higher production per capita are burdened by higher costs of coordinating production processes (Bettencourt, 2013). The deviation of the best fit line from linearity can also be attributed to how prices of agricultural goods respond to production levels, due to underlying risk averse nature of humans.

Deviations from the scaling relationship have been observed and attributed to other conditions (e.g., diverse local conditions in which organisms live). Deviations from the scaling relationship have been attributed to local conditions, such as phosphorus gradients, temperature and other environmental and physiological conditions that may control the uptake of metabolites from the environment, such as the inefficiency of networks in transporting metabolites from diverse sources to reaction sites, and how organisms allocate the assimilated metabolic energy to survival, growth and reproduction (Hou et al., 2008; Savage et al., 2004; Fontana and Della, 2016). While nature, through its bioenergetics laws, controls survival, maintenance and growth of an individual's biomass, reproduction in organisms is also often urged on by nature except for humans who can choose to delay the time to reproduce.

Industrialized regions, with advanced technologies, are expected to have higher rate of return on investing in human capital (that contributes to sustaining such high levels of technologies) than less developed economies. As nations industrialize, demand for skilled labor force rises, making investment in honing the skills of the youth, e.g., through education, more attractive (Lim, 2009). This incentivizes parents to reproduce less, e.g., in Europe, and invest more on developing the needed skills of fewer children, as interpreted by models of human capital and fertility (Becker et al., 1990; Kaplan, 1996). It is therefore expected that less developed regions are more constrained by the metabolic rate and are expected to exhibit the scaling relationship between birth rate per capita and water use per capita, assuming that lack of nutrients and under-weightness does not adversely affect the metabolic states of humans (Fontana and Della, 2016).

If water use controls (or is controlled by) the metabolic rate then technologically less developed regions should exclusively obey the power relationship and developed regions should deviate from the relationship. On the other hand, adverse effects of excessively low (high) body weight on metabolism and birth rate implies that poorest (richest) regions with food scarcity (abundance) such as Africa (North America and Oceania) should have lower than expected birth rate (Fontana and Della, 2016). This appears not to be the case for Africa, North America, and Oceania.

An explanation of deviations may lie in the spatial resolution of the analysis, which ignores variability within regions. Further, 
regions like Africa may have higher than expected birth rates to compensate for high child mortality or due to inefficient virtual water supply chains. Similarly, higher than expected (expectation being that birth rates are similar to Europe) birth rates in North America and Oceania may be attributed to proportionally higher wastage of virtual water at the consumption stage of the supply chain (Food and Agriculture Organization of the United Nations (2011)). Further exploration of the scaling relationship at the scale of nations is therefore warranted that additionally considers local co-variates such as soil fertility, diseases, supply chain efficiency and opportunity costs of raising off-springs.

Received: 17 November 2017 Accepted: 6 June 2018

Published online: 10 July 2018

\section{References}

Alcott B (2005) Jevons' paradox. Ecol Econ 54(1):9-21

Álvarez IC, Barbero J, Zofío JL, Panel A (2017) Data toolbox for MATLAB. J Stat Softw 76(6):1-27. https://doi.org/10.18637/jss.v076.i06

Banavar JR, Damuth J, Maritan A, Rinaldo A (2002) Supply-demand balance and metabolic scaling. Proc Natl Acad Sci 99(16):10506-10509. https://doi.org/ $10.1073 /$ pnas. 162216899

Bauch CT (2008) Wealth as a source of density dependence in human population growth. Oikos 117:1824-1832. https://doi.org/10.1111/j.1600-0706.2008. 17063.x

Becker GS, Murphy KM, Tamura R (1990) Human capital, fertility and economic growth. J Political Econ 98(5):S12-S37. Part 2

Bettencourt LMA (2013) The origin of scaling in cities. Science 340:1438-1441

Bettencourt LMA, Lobo J, Helbing D, Kühnert C, West GB (2007) Growth, innovation, scaling, and the pace of life in cities. Proc Natl Acad Sci 104 (17):7301-7306. https://doi.org/10.1073/pnas.0610172104

Bonhommeau L, Dubroca O, Le Pape J, Barde DM, Kaplan E, Chassot, Nieblas A-E (2013) Eating up the world's food web and the human trophic level. PNAS 10 (51):20617-20620. https://doi.org/10.1073/pnas.1305827110

Brown JH, Gillooly JF, Allen AP, Savage VM, West GB (2004) Towards a metabolic theory of ecology. Ecology 85:1771-1789. https://doi.org/10.1890/03-9000

Burger O, DeLong JP, Hamilton MJ (2011) Industrial energy use and the human life history. Sci Rep 1:56. https://doi.org/10.1038/srep0005

Burger JR, Weinberger VP, Marquet PA (2017) Extra-metabolic energy use and the rise in human hyper-density. Sci Rep 7:43869. https://doi.org/10.1038/ srep 43869

Chertow MR (2000) The IPAT equation and its variants. J Ind Ecol 4(4):13-29

Dalin C, Konar M, Hanasaki N, Rinaldo A, Rodriguez-Iturbe I (2012) Evolution of the global virtual water trade network. Proc Natl Acad Sci USA 109:5989-5994. https://doi.org/10.1073/pnas.1203176109

Fontana R, Della TS (2016) The deep correlation between energy metabolism and reproduction: a view on the effects of nutrition for women fertility. Nutrients 8(2):87. https://doi.org/10.3390/nu8020087

Food and Agriculture Organization of the United Nations (2011) Global food losses and food waste-Extent, causes and prevention. Rome, http://www.fao. org/docrep/014/mb060e/mb060e00.pdf

Hanasaki N, Inuzuka T, Kanae S, Oki T (2010) An estimation of global virtual water flow and sources of water withdrawal for major crops and livestock products using a global hydrological model. J Hydrol 384(3-4):232-244. https://doi.org/10.1016/j.jhydrol.2009.09.028, . ISSN 0022-1694

Hoekstra AY, Hung PQ (2002) Virtual Water Trade@: a quantification of virtual flows between nations in relation to international crop trade. Value of Water Research Report series No. 11, IHE Delft, http://waterfootprint.org/media/ downloads/Report11.pdf

Hou C, Zuo W, Moses ME, Woodruff WH, Brown JH, West GB (2008) Energy uptake and allocation during ontogeny. Science 322(5902):736-739. https:// doi.org/10.1126/science.1162302,

Kaplan H (1996) A theory of fertility and parental investment in traditional and modern human societies. Yearb Phys Anthropol 39:91-135

Konar M, Dalin C, Hanasaki N, Rinaldo A, Rodriguez-Iturbe I (2012) Temporal dynamics of blue and green virtual water trade networks. Water Resour Res 48(7):W07509

Konar M, Dalin C, Suweis S, Hanasaki N, Rinaldo A, Rodriguez-Iturbe I (2011) Water for food: The global virtual water trade network. Water Resour Res 47: W05520. https://doi.org/10.1029/2010WR010307
Lim LL (2009) Female labour- force participation. Popul Bull U Nation-Complet Fertil Transit Special Issue 48/49:203-221

Lutz W (2006) Fertility rates and future population trends: will Europe's birth rate recover or continue to decline? Int J Androl 29:25-33. https://doi.org/ 10.1111/j.1365-2605.2005.00639.x

Mace R (2008) Reproducing in cities. Science 319(5864):764-766. https://doi.org/ $10.1126 /$ science. 1153960

Moses ME, Brown JH (2003) Allometry of human fertility and energy use. Ecol Lett 6:295-300. https://doi.org/10.1046/j.1461-0248.2003.00446.x

Pande S, Ertsen M, Sivapalan M (2014) Endogenous technological and population change under increasing water scarcity. Hydrol Earth Syst Sci 18:3239-3258. https://doi.org/10.5194/hess-18-3239-2014,

Savage VM, Deeds EJ, Fontana W (2008) Sizing up allometric scaling theory. PLoS Comput Biol 4(9):e1000171. https://doi.org/10.1371/journal.pcbi.1000171

Savage VM, Gillooly JF, Brown JH, West GB, Charnov EL (2004) Effects of body size and temperature on population growth. Am Nat 163(3):429-441

Sears L, Caparelli J, Lee C, Pan D, Strandberg G, Vuu L, Lin C-YC (2018) Lawell, Jevons' Paradox and Efficient Irrigation Technology. Sustainability 10:1590

Shiklomanov IA (2003) World water use and water availability. In: Shiklomanov IA, Rodda JC (eds) World Water Resources at the Beginning of the 21st Century. Cambridge University Press, Cambridge

Srinivasan V, Konar M, Sivapalan M (2017) A dynamic framework for water security. Water Secur, Elsevier 1:12-20. https://doi.org/10.1016/j.wasec. 2017.03.001

United Nations Department of Economic and Social Affairs (2015) Population Division, World population prospects: The 2015 Revision, DVD Edition

United Nations Department of Economic and Social Affairs (2018) Statistics Division, National Accounts Main Aggegrates Database

Zhang J, Yu T (2010) Allometric scaling of countries. Phys A Stat Mech its Appl 389(21):4887-4896. https://doi.org/10.1016/j.physa.2010.06.059

Zimmer D, Renault D (2003) Virtual water in food production and global trade: Review of methodological issues and preliminary results. In: Hoekstra AY (ed) Virtual Water Trade: Proceedings of the International Expert Meeting on Virtual Water Trade, Value of Water Research Report Series n. 12. UNESCO-IHE, Institute for Water Education, Delft

\section{Data availability}

The datasets analyzed in the study are obtained from Shiklomanov (2003), Hoekstra and Hung (2002), United Nations (2015), Zimmer and Renault (2003) and Konar et al. (2011, 2012). The datasets generated in the current study and plotted in the figures are available in the Dataverse repository: https://doi.org/10.7910/DVN/N1FRI8.

\section{Acknowledgements}

The authors are grateful to the editor, two anonymous referees, Murugesu Sivapalan, Megan Konar, Naota Hanasaki, Marc Bierkens, Ashish Sharma and Markus Disse for their critical comments on various versions of the paper. The authors are solely responsible for any error or omissions that may remain.

\section{Additional information}

Competing interests: The authors declare no competing interests.

Reprints and permission information is available online at http://www.nature.com/ reprints

Publisher's note: Springer Nature remains neutral with regard to jurisdictional claims in published maps and institutional affiliations.

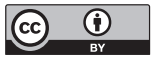

Open Access This article is licensed under a Creative Commons Attribution 4.0 International License, which permits use, sharing, adaptation, distribution and reproduction in any medium or format, as long as you give appropriate credit to the original author(s) and the source, provide a link to the Creative Commons license, and indicate if changes were made. The images or other third party material in this article are included in the article's Creative Commons license, unles indicated otherwise in a credit line to the material. If material is not included in the article's Creative Commons license and your intended use is not permitted by statutory regulation or exceeds the permitted use, you will need to obtain permission directly from the copyright holder. To view a copy of this license, visit http://creativecommons.org/ licenses/by/4.0/.

(C) The Author(s) 2018 